\title{
Does alcohol contribute to accident and emergency department attendance in elderly people?
}

\author{
Veronica van der Pol, Helen Rodgers, Philip Aitken, Oliver James, Richard Curless
}

\begin{abstract}
Objective-To evaluate the possible contribution of alcohol to presentation of elderly subjects at a hospital accident and emergency (A\&E) department.

Methods-105 patients aged 70 years and over who attended the department were interviewed by a single observer using a structured questionnaire based on previously validated general population surveys. Details of alcohol consumption within the previous 24 hours were recorded. Usual consumption of alcohol in the preceding 12 months was estimated by the quantity frequency method. Alcohol dependence was screened for by the CAGE questionnaire. An assessment of disability was made using the Barthel index. Breath alcohol was measured.

Results-In only $2 \%$ of attenders was alcohol thought to be a contributory factor. Breath alcohol measurements were technically unsatisfactory in this age group. Regular drinkers were functionally and socially more independent than nonregular drinkers. Drinking patterns in this age group may partly be determined by the physical ability to obtain alcohol.

Conclusions-Alcohol was not found to be a major factor in $A \& E$ attendance in elderily people.

( $\mathcal{F}$ Accid Emerg Med 1996;13:258-260)
\end{abstract}

Key terms: alcohol; elderly; accident and emergency departments

The contribution of alcohol to health problems in the elderly, especially the very elderly, is unclear. Older people could be more susceptible to adverse effects from alcohol because of age related changes in alcohol metabolism, interactions with other medications, and coexistent medical problems. We have previously shown that $18 \%$ of people aged over 60 in Newcastle drink more than current recommended guidelines. ${ }^{1}$

In an inner city London hospital, $19.4 \%$ of hospital admissions in those under age 60 years were alcohol related compared to $2 \cdot 8 \%$ in those over age $60 .^{2}$ A limited survey of domiciliary visits found $1 \cdot 7 \%$ of the elderly seeking admission to hospital to be addicted to alcohol. ${ }^{3}$ Blood alcohol was detectable in $2.8 \%$ of patients admitted acutely to a geriatric ward. ${ }^{4}$ We report the findings of a cross sectional survey evaluating the possible contribution of alcohol to presentation of elderly subjects at a hospital accident and emergency (A\&E) department. In addition, we examine the relations between patterns of drinking, functional abilities and medical problems.

\section{Methods}

The accident and emergency department of Newcastle General Hospital provides medical services for a predominantly urban population. All major specialties are present at this hospital and at the time of the survey all acute admissions, whether self referrals or through the general practitioner, passed through the department.

Patients aged 70 years and over who attended the department were eligible for inclusion in the study. Subjects were interviewed by a single observer (VvdP) using a structured questionnaire based on previously validated general population surveys. ${ }^{5}$ The observer worked an eight hour shift system (including nights and weekends) over a four week period designed to give a representative sample of all acute attendances at the department.

Details were recorded of alcohol consumption within the previous 24 hours. Usual consumption of alcohol in the preceding 12 months was estimated by the quantity frequency method. Alcohol dependence was screened for by the CAGE questionnaire. ${ }^{6}$ An assessment of disability was made using the Barthel index, a widely used and validated measure of activities of daily living in geriatric medicine. ${ }^{78}$ The observer assessed the role of alcohol in the patients' presentation to the $A \& E$ department using defined guidelines before asking the patient to blow into a Lion Alcometer. The initial proposal was to take blood alcohol level simultaneously, but ethics approval for this was not granted.

The study was approved by the Joint Newcastle ethics committee. Non-parametric statistical methods were employed. Between group comparisons were made by the $\chi^{2}$ test with Yates correction where appropriate and the odds ratio (OR) with $95 \%$ confidence intervals (CI).

\section{Results}

Within the study period, 263 patients within the target age group attended the $A \& E$ department, $105(40 \%)$ of whom presented within the shift sampling frame and comprise the study population. All were interviewed. Demographic details of the 158 patients 


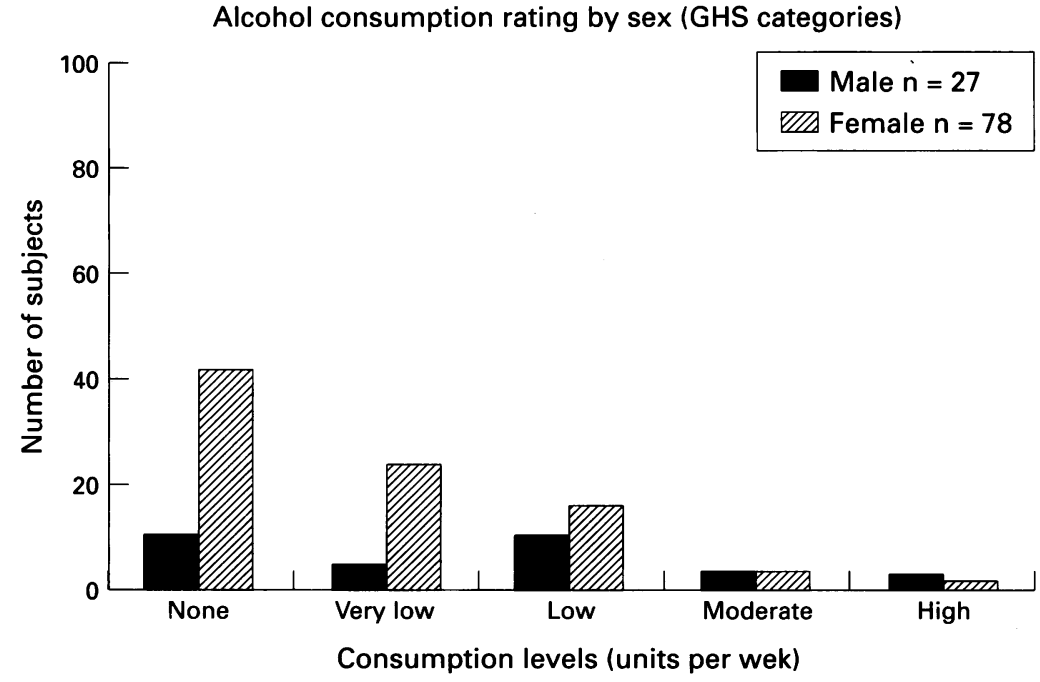

Alcohol consumption categories by sex (units per week, men and women respectively); non (abstainers); very low (<1); low (1-10, 1-7); moderate (11-21; 8-14); high (>21, >14). ${ }^{5}$

attending outside the sampling periods were reviewed and were not found to differ from the study population.

Respondents' median age was 77 years (range 70 to 96 ): 27 men and 78 women. Thirty four per cent were living with their spouse, but nearly half the sample $(44 \%)$ lived alone. Fifty one per cent were in contact with at least one community agency. The commonest reason for attendance was a medical condition in $59(55 \%)$, followed by minor trauma in $39(38 \%)$. Only six patients had a surgical presentation, and there was

Table 1 Self reported health problems by drinking pattern ${ }^{\star}$. Comparison of regular versus non-regular drinkers [odds ratios (OR): 95\% confidence intervals (CI)]

\begin{tabular}{lccll}
\hline Health problem & \multicolumn{3}{l}{ Drinking pattern } & \\
\cline { 2 - 5 } & $\begin{array}{l}\text { Regular } \\
n=27\end{array}$ & $\begin{array}{l}\text { Sporadic } \\
n=29\end{array}$ & $\begin{array}{l}\text { Abstainers } \\
n=49\end{array}$ & $\begin{array}{l}\text { Regular v Non-regular } \\
\text { OR }(95 \% \text { CI }\end{array}$ \\
\hline Back & 7 & 6 & 18 & $0 \cdot 79(0 \cdot 28$ to $2 \cdot 08)$ \\
Joints & 12 & 20 & 30 & $0 \cdot 45(0 \cdot 16$ to $1 \cdot 09)$ \\
Eyesight & 9 & 11 & 21 & $0 \cdot 72(0 \cdot 27$ to $1 \cdot 77)$ \\
Hearing & 12 & 15 & 28 & $0 \cdot 65(0 \cdot 25$ to $1 \cdot 57)$ \\
Blood pressure & 5 & 7 & 11 & $0 \cdot 76(0 \cdot 24$ to $2 \cdot 22)$ \\
Nerves & 12 & 13 & 16 & $1 \cdot 35(0 \cdot 55$ to $3 \cdot 53)$ \\
Blackouts & 3 & 2 & 7 & $0.96(0 \cdot 27$ to $4 \cdot 19)$ \\
Dizziness & 8 & 11 & 21 & $0 \cdot 61(0 \cdot 22$ to $1 \cdot 49)$ \\
Falls & 6 & 9 & 21 & $0 \cdot 46(0 \cdot 15$ to $1 \cdot 15)$ \\
Ulcers & 8 & 10 & 13 & $1 \cdot 01(0 \cdot 37$ to $2 \cdot 72)$ \\
Jaundice & 2 & 3 & 6 & $0 \cdot 61(0 \cdot 10$ to $2 \cdot 61)$ \\
\hline
\end{tabular}

^Regular: weekly or more frequent; Sporadic: less than weekly; Abstainers: no alcohol consumption; Non-regular: abstainers and sporadic.

Table 2 Social service input and Barthel ADL score $<14$ by drinking pattern ${ }^{\star}$. Comparison of regular versus non-regular drinkers [odds ratios (OR): $95 \%$ confidence intervals (CI)]

\begin{tabular}{|c|c|c|c|c|}
\hline \multirow[t]{2}{*}{ Service } & \multicolumn{4}{|c|}{ Drinking pattern } \\
\hline & $\begin{array}{l}\text { Regular } \\
n=27\end{array}$ & $\begin{array}{l}\text { Sporadic } \\
n=29\end{array}$ & $\begin{array}{l}\text { Abstainers } \\
n=49\end{array}$ & $\begin{array}{l}\text { Regular v Non-regular } \\
\text { OR }(95 \% \text { CI })\end{array}$ \\
\hline Home help & 5 & 12 & 17 & $0.38(0.11$ to 0.99$)$ \\
\hline Meals on Wheels & 3 & 1 & 0 & $9.63(1.38$ to 1305.72$)$ \\
\hline Luncheon club & 1 & 3 & 3 & $0.46(0.01$ to 2.63$)$ \\
\hline Social worker & 2 & 9 & 6 & $0.34(0.05$ to 1.09$)$ \\
\hline Bath attendant & 1 & 7 & 7 & $0.18(0.02$ to 0.64$)$ \\
\hline District nurse & 2 & 5 & 12 & $0.29(0.04$ to 0.90$)$ \\
\hline Day centre & 3 & 4 & 5 & $0.61(0.10$ to 2.61$)$ \\
\hline Barthel $<14$ & 1 & 7 & 9 & $0.15(0.02$ to 0.53$)$ \\
\hline
\end{tabular}

${ }^{\star}$ Regular: weekly or more frequent; Sporadic: less than weekly; Abstainers: no alcohol consumption; Non-regular: abstainers and sporadic. one case of self poisoning. There were no differences between patients attending with medical problems or trauma in terms of age, sex, and reported alcohol intake.

The figure shows the alcohol consumption ratings for men and women, in general household survey categories. ${ }^{5}$ The majority of respondents were either abstainers ( $n=49$; $47 \%)$ or very low consumers $(n=26 ; 25 \%)$. Only three subjects (3\%) fell into the high category. Median weekly alcohol intake was very low at 0.043 units. Only two subjects were identified as alcohol dependent using the CAGE questionnaire. Thirty seven patients (36\%) admitted to having a higher alcohol intake in the past, but 29 of these had reduced their intake over 20 years previously; among this group median weekly intake had been 11.4 and 8.8 units for males and females respectively. None admitted to increasing their alcohol intake after the age of 70 .

Few patients $(n=8)$ reported having drunk within the 24 hours before their attendance. The observer assessed only one patient as mildly intoxicated (on the basis of behaviour, dysarthria, and alcohol smelt on the breath) and found alcohol to be directly (drugs and alcohol overdoses) or indirectly (patients with known alcohol cirrhosis and encephalopathy) contributory to the attendance in only two and one subjects respectively. Measurement of breath alcohol was attempted in all cases. Unfortunately, $45 \%$ were unable to use the Alcometer satisfactorily, while a further $12 \%$ refused. Breath alcohol was not detectable in all patients in whom it was measured.

Those who drank less than weekly (sporadic; $n=29)$ and abstainers $(n=49)$ were classified as non-regular drinkers $(n=78)$ whereas those drinking weekly or more frequently were regarded as regular drinkers $(n=27)$. Regular as opposed to non-regular drinkers were significantly more likely to be male $(11 / 27 v$ $16 / 78 ; P<0.05)$. There were trends towards their being younger (age 75 or less 14/27 $v$ $31 / 78$; odds ratio $1.63(0.67$ to 4.35$)$ and current smokers $8 / 27 v 14 / 78$; odds ratio 1.92 $(0.66$ to 6.69$)$.

Subjects were asked about specific medical problems, particularly those in which alcohol may be a contributory factor (table 1). Forty one $(40 \%)$ reported nervous illness, $40(39 \%)$ dizziness, $36(35 \%)$ falls, $31(30 \%)$ ulcers/ dyspepsia, 23 (23\%) hypertension, $12(12 \%)$ blackouts, and $11(11 \%)$ jaundice or liver disease. The frequencies of such conditions between regular and non-regular drinkers were compared using odds ratios. There were trends for regular drinkers to report joint problems, dizziness, and falls less often.

The median Barthel activities of daily living score was 19 ( 3 to 20 ), with 40 subjects (39\%) scoring maximally. Scores less than 14 suggest significant functional limitation. Regular drinkers had less input from the home help, social worker, district nurse, or bath attendant (table 2). Further, regular drinkers were less likely to have a Barthel score under 14, suggesting that they had greater functional independence. 


\section{Discussion}

Detecting alcohol misuse is particularly difficult in older people. We therefore used questions from previously validated general population surveys and a widely used screening instrument for alcohol dependency. The contribution of recent alcohol consumption to the acute presentation of elderly people to the A\&E department appears very small - some $2 \%$. This is consistent with other British studies in this age group ${ }^{9}$ but American data have suggested that as many as $14 \%$ of over 65 year olds attending $A \& E$ are current alcohol abusers. ${ }^{10}$ In contrast, a previous survey in the same $A \& E$ department found $13 \%$ of unselected attenders to have excess blood alcohol (but no information was available on the age of these individuals). ${ }^{11}$ It had been anticipated that breath alcohol would be an acceptable objective measurement of recent alcohol intake. However, difficulties were encountered with this approach in elderly people because of failures in breath strength, coordination, and understanding because of physical illness. We suggest that this method of quantifying alcohol levels is not applicable to the elderly. In addition, $12 \%$ of the sample refused to perform a breath alcohol reading which may have led to an underestimation of the contribution of alcohol to $A \& E$ attendance.

Only a very small proportion of these elderly patients were drinking above recommended sensible limits. Few had alcohol related problems detected by the CAGE screening instrument. While one third had previously had a higher regular alcohol intake, the majority of respondents had cut down many years ago. An earlier community survey in Newcastle found much higher rates of heavy drinking (13\% of those over 60 at risk of alcoholic liver disease). ${ }^{1}$ Since this group is not presenting acutely to hospital, it will be important to determine whether they are known to either outpatient or community services.
Regular drinkers appear to have better functional status and were less likely to be in touch with a community agency. Furthermore, there were trends towards less frequent reporting of health problems concerned with mobility (for example, joints, dizziness, and falls) in regular drinkers. This may suggest that drinking patterns in elderly people are partly determined by their physical ability to obtain alcohol. Alternatively, regular drinkers might appear more independent because they under report problems which they perceive as linked to their alcohol intake.

This study has not found alcohol to be a major factor in $A \& E$ attendance in elderly people. Further work to elucidate those factors that influence alcohol consumption in the general elderly population and the resultant effects on personal health states of that population is indicated.

We thank Mr David Milne and his staff at the accident and emergency department for their assistance throughout this study.

1 Bridgewater R, Potter J, James OFW. Alcohol consumption and dependence in elderly patients in an urban community. $B M 7$ 1987;295:884-5.

2 Taylor CL, Passmore N, Kilbane P, Davies R. Prospective study of alcohol related admissions in an inner city hospital. Lancet 1986;ii:265-7.

3 Droller $\mathrm{H}$. Some aspects of alcoholism in the elderly. Lancet 1964;ii:137-9.

4 Penn ND, Corrado OJ, Pitchfork LJ, Evans RT, Mascie Taylor BH. Blood alcohol levels in acute elderly admissions to hospital. Postgrad Med $\mathcal{F}$ 1989;65:20-1.

5 Green H. General household survey 1986. Drinking. Serial GHS 16(suppl A). London: HMSO, 1986.

6 Mayfield D, McLeod G, Hall P. The CAGE questionnaire: validation of a new alcoholism screening instrument. $\mathrm{Am}$ validation of a new alcoholism
$\exists$ Psychiatry $1974 ; 131: 1121-3$.

7 Mahoney FI, Barthel DW. Functional evaluation: the Barthel Index. Maryland State Med $¥$ 1965;22:61-5.

8 Royal College of Physicians of London and British Geriatrics Society. Standardised assessment scales for elderly people. London, Royal College of Physicians, 1992.

9 Mangion DM, Platt JS, Syam V. Alcohol and acute medical admission of elderly people. Age Ageing 1992;21:362-7.

10 Adams WL, Magruder-Habib K, Trued S, et al. Alcohol abuse in elderly emergency department patients. $\mathcal{f} \mathrm{Am}$ Geriatr Soc 1992;40:1236-40.

11 Rhodes M, Carlson G, Dunn J, et al. All day drinking - its impact on an Accident and Emergency Department. Health Trends 1990;22:120-1. 